\title{
DENSIDADE DO SISTEMA RADICULAR DA BANANEIRA 'PACOVAN' SOB IRRIGAÇÃO POR ASPERSÃO ${ }^{1}$
}

\author{
RAIMUNDO LACERDA FILHO², ANA VERUSKA CRUZ DA SILVA³, VANDER MENDONÇA4, \\ JOSÉ CELESMÁRIO TAVARES ${ }^{4}$
}

\begin{abstract}
RESUMO - O presente trabalho foi realizado no município de Governador Dix-Sept Rosado, microrregião Açu-Apodi, no Estado do Rio Grande do Norte, tendo como objetivo verificar os efeitos do sistema de irrigação por aspersão na densidade do sistema radicular da bananeira 'Pacovan'. O delineamento experimental utilizado foi o de blocos casualizados, em esquema de parcelas subdivididas, com cinco repetições. Os tratamentos foram duas amostragens por planta, realizadas do lado contrário ao da emissão da inflorescência, formando um ângulo de $45^{\circ}$. Em cada amostragem, foram realizadas quatro retiradas do material de solo a distâncias de $20 \mathrm{~cm}$, sendo a primeira a $30 \mathrm{~cm}$ e a última a $90 \mathrm{~cm}$ do pseudocaule. A análise dos dados demonstrou que ocorreu redução linear no peso fresco e na densidade de comprimento de raízes da bananeira em função da profundidade do solo. Em relação à distância do pseudocaule da bananeira, tanto o peso fresco quanto a densidade de comprimento de raízes não mostraram resultados significativos.
\end{abstract}

Termos para indexação: Musa spp., raízes, matéria fresca

\section{ROOT SYSTEM DENSITY OF 'PACOVAN' BANANA PLANT UNDER SPRINKLER IRRIGATION}

\begin{abstract}
The present work was conducted at Governador Dix-Sept Rosado County, microregion Açu-Apodi, in the state of Rio Grande do Norte and its objective was to study the effects of sprinkler irrigation system on the density of the root system of 'Pacovan' banana plants. The experiment followed a completely randomized block design, in a split-plot scheme, with five replications. The treatments were two sampling groups, taken per plant, and in the opposite side of the inflorescence emission, forming between them an angle of $45^{\circ}$. In each sampling group, four samples containing soil material were collected at intervals of $20 \mathrm{~cm}$, so the first was distant $30 \mathrm{~cm}$ and the last $90 \mathrm{~cm}$ from the pseudostem. Data analysis showed that occurred a linear reduction in root fresh weight and in lenght of roots density, in replications to soil depth. For the distance from the plant pseudostem there were no significant differences between samples, both for root fresh weight and lenght of roots density.
\end{abstract}

Index terms: Musa spp., roots, fresh matter.

O Nordeste brasileiro detém 35\% da área total de bananeira do País, possuindo em quase toda a sua extensão condições climáticas propícias para o desenvolvimento e produção da cultura. Apesar dessas condições tão favoráveis, a produtividade obtida tem sido aquém do seu potencial, devido à não-utilização das tecnologias disponíveis e adequadas para a sua exploração.

Para que se eleve esta produtividade, é necessário estabelecer uma política de incentivo ao cultivo, bem como a adoção de tecnologias adequadas para a região, especialmente no que se refere à irrigação, tendo em vista as condições de precipitações pluviométricas instáveis nas áreas de maior produção.

O sistema radicular da bananeira apresenta um comportamento superficial. As raízes se estendem lateralmente a uma distância de 5,2 m da planta, descendo geralmente a uma profundidade de $0,75 \mathrm{~m}$. O sistema radicular é um importante componente estrutural da planta, mas mesmo assim poucos trabalhos têm sido realizados no campo em relação aos seus diferentes estágios de desenvolvimento. Bananeiras plantadas em solos férteis ou bem adubados, bem drenados e providos de umidade suficiente, apresentam o seu sistema radicular bastante viçoso, ao passo que em solos pobres, sem fertilizantes e sem drenagem, as raízes apresentam-se delgadas e em pequeno número (Moreira, 1975).

Segundo Follet et al. (1994), o excesso de umidade nas camadas superiores do solo provoca diminuição no crescimento das ramificações, provavelmente pela pouca aeração, sendo que o mesmo poderá ocorrer em camadas mais profundas quando da existência da água disponível. Desta forma, é de se esperar que o método de irrigação possa interferir no maior ou menor desenvolvimento das raízes, influindo, portanto, no crescimento vegetativo e na produção da bananeira. Moura (1986), trabalhando com o sistema de irrigação por gotejamento tipo "Spaghetti" ou "Fitilho", relatou que a maior concentração de raízes estava em torno do rizoma, na profundidade entre 0 e $0,15 \mathrm{~m}$ e na distância de $0,30 \mathrm{~m}$ do pseudocaule da bananeira 'Nanica'.
De acordo com Primavesi (1984), o comprimento e o volume de raízes variam segundo a espécie, a variedade do vegetal, o solo e a disponibilidade de água. Mielniczuk (1990) relata que o desenvolvimento de raízes apresenta boa correlação com as características físicas dos solos, tais como densidade, resistência à penetração e espaço aéreo. Para Moura (1986), o volume de raízes da bananeira Nanica diminuiu à medida que se afastou do pseudocaule da bananeira. Essa redução foi de tal ordem que aos $90 \mathrm{~cm}$ de distância do pseudocaule se encontrou apenas 15,38\% do volume total levantado.

Objetivou-se com este trabalho verificar os efeitos do sistema de irrigação por aspersão na densidade do sistema radicular da bananeira 'Pacovan'.

A área experimental localiza-se no município de Governador DixSept Rosado, microrregião Açu-Apodi do Estado do Rio Grande do Norte. Este município acha-se a 5 ${ }^{\circ} 28^{\prime}$ de Latitude Sul e 37॰31' de Longitude Oeste. De acordo com a classificação de Köeppen, o clima é do tipo BSw, semi-árido muito quente, apresentando uma precipitação média anual de $406 \mathrm{~mm}$. O solo da área, localizada à margem direita do Rio Mossoró, é do tipo Aluvial Eutrófico. A análise granulométrica (Tabela 1) foi realizada no Laboratório de Análise de Solos da Escola Superior de Agricultura de Mossoró (ESAM), segundo a metodologia preconizada pela EMBRAPA (1969).

Utilizou-se a cultivar Pacovan, plantada no espaçamento $3 \mathrm{~m} \times 2$ $\mathrm{m}$. As amostragens de material de solo contendo raízes foram tomadas por ocasião da emissão da inflorescência, que, de acordo com Moreira (1975), é o período no qual a planta não mais emite raízes. Foi utilizado o sistema de irrigação por aspersão com pressão de $300 \mathrm{KPa}$ e vazão de $3,63 \mathrm{~m}^{3} / \mathrm{h}$.

$\mathrm{O}$ experimento foi conduzido no delineamento em blocos casualizados, em esquema de parcelas subdivididas, com cinco repetições. Para estimativa de densidade radicular, foram feitas amostragens e determinações. As amostragens, em número de duas por planta, foram realizadas do lado contrário ao da emissão da inflorescência, formando um

\footnotetext{
${ }^{1}$ (Trabalho 043/2003). Recebido: 21/05/2003. Aceito para publicação: 11/08/2004.

${ }^{2}$ Eng $^{\circ}$. Agrônomo. Escola Superior de Agricultura de Mossoró (ESAM).

${ }^{3}$ Eng $^{\text {a }}$.Agrônoma, DSc., Professora Visitante da Universidade Federal de Sergipe. E-mail: anaveruska@ufs.br

${ }^{4}$ Eng $^{\circ}$ Agrônomo, MSc., Doutorando em Agronomia: Fitotecnia - UFLA.

${ }^{5}$ Eng $^{\text {o }}$ Agrônomo, DSc., Professor do Departamento de Fitotecnia da ESAM
} 
TABELA 1 - Análise granulométrica em solo Aluvial Eutrófico. Dix-Sept Rosado, ESAM - Mossoró-RN.

\begin{tabular}{cccccc}
\hline $\begin{array}{c}\text { Amostra } \\
\left(\mathbf{N}^{\circ}\right)\end{array}$ & $\begin{array}{c}\text { Profundid } \\
\text { ade }(\mathbf{c m})\end{array}$ & $\begin{array}{c}\text { Areia } \\
\text { Grossa } \\
(\%)\end{array}$ & $\begin{array}{c}\text { Areia } \\
\text { Fina } \\
(\%)\end{array}$ & $\begin{array}{c}\text { Silte } \\
(\%)\end{array}$ & $\begin{array}{c}\text { Argila } \\
(\%)\end{array}$ \\
\hline 1 & $0-6$ & 19 & 35 & 27 & 19 \\
2 & $6-13$ & 19 & 52 & 13 & 16 \\
3 & $13-18$ & 13 & 40 & 31 & 16 \\
4 & $18-36$ & 18 & 38 & 43 & 1 \\
5 & $36-54$ & 14 & 71 & 12 & 3 \\
6 & $54-94$ & 37 & 54 & 4 & 2 \\
7 & $94-105$ & 2 & 62 & 21 & 15 \\
8 & $105-122$ & 2 & 74 & 12 & 12 \\
9 & $122+$ & 8 & 57 & 20 & 15 \\
\hline
\end{tabular}

ângulo de $45^{\circ}$. Em cada amostragem, foram realizadas quatro retiradas do material a distâncias prefixadas de $20 \mathrm{~cm}$ entre cada ponto de coleta, sendo o primeiro a $30 \mathrm{~cm}$ e o último a $90 \mathrm{~cm}$ do pseudocaule da bananeira.

O material de solo contendo as raízes foi coletado nas profundidades de $0-0,15 \mathrm{~m} ; 0,15-0,30 \mathrm{~m} ; 0,30-0,45 \mathrm{~m} ; 0,45-0,60 \mathrm{~m}$, utilizandose de um trado com $0,71 \mathrm{~m}$ de diâmetro e $0,65 \mathrm{~m}$ de comprimento, contendo em seu interior um tubo de PVC com 0,60 m de comprimento, conforme metodologia utilizada por Moura (1986). As raízes, depois de separadas do material de solo, foram lavadas e pesadas numa balança de precisão para a determinação do peso fresco. Logo depois, foram transferidas para recipientes de vidro contendo água destilada e armazenadas em refrigerador.

Posteriormente, foi efetuada a estimativa do comprimento das raízes, utilizando-se do método das quadrículas, proposto por Marsh (1971) e Tennant (1975), usando-se uma grade de $18 \mathrm{~cm}$ x $25 \mathrm{~cm}$ com malhas de 2,0 $\mathrm{cm}$. Para tal, as raízes foram dispostas ao acaso em uma bandeja transparente para contagem do número de interseções, estas representadas pelos pontos de cruzamento entre uma raiz e as linhas que formam as malhas. O valor foi aplicado na fórmula $\mathrm{C}=\mathrm{N}$. L. 11/14, onde: $\mathrm{C}=$ Comprimento de raízes em cm; $\mathrm{N}=$ Número de interseções; $\mathrm{L}=$ Lado da malha.

Os comprimentos estimados divididos pelo volume das amostras de material do solo $\left(593,58 \mathrm{~cm}^{3}\right)$ forneceram resultados expressos em $\mathrm{cm} /$ $\mathrm{cm}^{3}$ para a densidade de comprimento de raízes.

O peso fresco diminuiu acentuadamente com o aprofundamento da amostragem. Pode-se observar ainda que a maior concentração de raízes se deu nos primeiros $15 \mathrm{~cm}$ de profundidade com percentual aproximado de 40,9\% (Figura 1). Com relação às diferentes distâncias do pseudocaule, não houve diferenças. A análise estatística utilizada foi regressão linear para as variáveis peso fresco e densidade de comprimento de raízes. Na Tabela 2, estão os valores encontrados nas equações de regressão linear para peso fresco e densidade de comprimento, que apresentaram $\mathrm{R}^{2}$ altos, de 0,964 e de 0,978 , respectivamente, sendo que estas equações estão representadas na Figura 1.
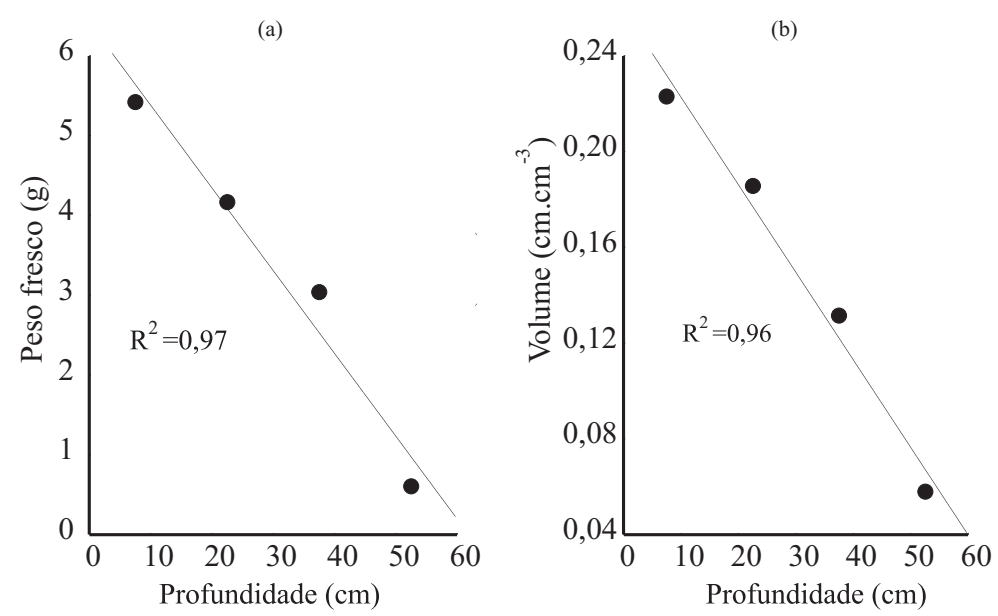

FIGURA 1 - Peso fresco $(\mathrm{g})$ e volume $\left(\mathrm{cm} / \mathrm{cm}^{3}\right)$ de raízes da bananeira 'Pacovan' em função da profundidade $(\mathrm{cm})$ de amostragem. ESAM, Mossoró- RN
TABELA 2 - Valores encontrados para peso fresco (g), densidade de comprimente $\left(\mathrm{cm} / \mathrm{cm}^{3}\right)$ e parâmetros da equação de regressão linear para de raízes da bananeira 'Pacovan' em função da profundidade $(\mathrm{cm})$ de amostragem. ESAM, Mossoró - RN.

\begin{tabular}{ccc}
\hline Profundidade & Peso fresco & $\begin{array}{c}\text { Densidade de } \\
\text { comprimento } \\
\text { (cm.cm }\end{array}$ \\
\hline$[00-15]$ & 5,42 & 0,22 \\
{$[15-30]$} & 4,17 & 0,19 \\
{$[30-45]$} & 3,04 & 0,13 \\
{$[45-60]$} & 0,61 & 0,06 \\
\hline 0 & 6,4197 & 0,2593 \\
1 & $-0,1037$ & $-0,0037$ \\
$\mathrm{R}^{2}$ & 0,964 & 0,978 \\
\hline
\end{tabular}

Observando-se a Figura 1, nota-se um comportamento semelhante quanto à densidade de comprimento das raízes, sendo que, a $0,30 \mathrm{~m}$ de profundidade, se encontrou $72,4 \%$ da densidade de comprimento das raízes e entre $0,45-0,60 \mathrm{~m}$, apenas $4,6 \%$. Resultado similar também foi verificado por Moura (1986).

Ao verificar os efeitos do sistema de irrigação por aspersão na densidade do sistema radicular da bananeira 'Pacovan', instalado num solo Aluvial Eutrófico, observou-se que o peso fresco e a densidade de comprimento das raízes diminuíram acentuadamente com o aprofundamento das amostragens, não ocorrendo diferenças com relação às distâncias do pseudocaule. Esses resultados estão relacionados, provavelmente, à boa fertilidade e elevada retenção de umidade nos primeiros $0,15 \mathrm{~m}$ de profundidade do solo, fazendo com que o sistema radicular da cultivar Pacovan permanecesse concentrado nesta profundidade. $\mathrm{O}$ solo em que foi instalado o experimento apresenta características físicas com elevada percentagem de silte (Tabela 1), o que poderá ocasionar problemas de rigidez do solo caso não se mantenha com umidade adequada.

De acordo como foi conduzido o presente trabalho, pode-se concluir que: a)ocorreu redução linear no peso fresco e na densidade de comprimento de raízes em relação ao aprofundamento da amostragem; b) a maior e a menor concentração das raízes, com relação ao peso fresco e à densidade de comprimento, foi da ordem de $40,9 \%$ e $36,7 \%$ e de $4,6 \%$ e $10,0 \%$, respectivamente, nas profundidades de $0-0,15 \mathrm{~m}$ e 0,45-0,60 m; c) o peso fresco e a densidade de comprimento das diferentes distâncias do pseudocaule da bananeira 'Pacovan' não apresentaram diferenças estatisticamente significativas.

\section{REFERÊNCIAS}

EMBRAPA. Serviço Nacional de Levantamento e Conservação de Solos. Manual de métodos de análise de solos. Rio de Janeiro, 1969.

FOLLET, R.F.; ALLMARAS, R.R.; REICHMAN, G.A. Distribuition of corn roots in sandy soil with a declining water table. Agronomy Journal, Madison, v.66, n.2, p.288-292, 1994.

MARSH, B. Measurements of lenght en ranlon arrangments of lines. Journal of Applied Ecology, Oxford, v.8, n.1, p.265-267, 1971.

MIELNICZUK, J. Desenvolvimento de raízes como método de avaliação das práticas de manejo do solo. In: CONGRESSO BRASILEIRO E ENCONTRONACIONALDE PESQUISA SOBRECONSERVAÇÃO DO SOLO, 8., 1990, Londrina. Resumos...Londrina: UEL, 1990. 97p. MOREIRA, R.S. Curso de bananicultura. São Gonçalo: BNB, 1975. 95p.

MOURA, A.R.B. Estimativa da densidade radicular da bananeira Nanica submetida a um sistema não convencional. In: CONGRESSO BRASILEIRO DE FRUTICULTURA, 8., Brasília. Anais.....Brasília: SBF, 1986. p.83-86.

PRIMAVESI, A. Manejo ecológico do solo: a agricultura em regiões tropicais. São Paulo: Nobel, 1984. 540p.

TENNANT, D.A. Test of a modifield line intersect method of estimating root lenght. Journal of Ecology, Oxford, v.63, n.3, p.995-1001, 1975. 